\title{
NOTAS A UN ANÁLISIS DE LA MUJER GRIEGA ANTIGUA
}

\author{
María Ester Conejo
}

\begin{abstract}
The following article is an analysis of the role played by women in Greek society. It purports to present an innovative perspective on the views and ideas aboout Greek womanwood.
\end{abstract}

Entre las civilizaciones antiguas, Grecia y Roma son las más cercanas a nosotros, no solo en tiempo y espacio, sino también en espíritu, pues de ellas hemos heredado el núcleo de lo que "civilización occidental" significa, con todos los rasgos, positivos o negativos, que de ellas heredó la nuestra.

Aún con esta cercanía, la mentalidad de los antiguos griegos permanece difícil de aprehender, pues su existencia era muy diferente de la nuestra. De ahí la necesidad de que, para poder conocerlos, entenderlos y extraer algún provecho de este conocimiento, debamos olvidar por un momento, nuestras ideas actuales y tratar de sumergirnos en ese mundo brillante y atrayente, a la vez, un poco nebuloso y fragmentario. Al ponernos en su lugar, dentro de sus circunstancias, quizás se pueda, hasta cierto punto, compartir con ellos su modo de vida, y en algún grado, entender su sabiduría, reconocer sus fallas y extraer las mil y una lecciones que esta cultura nos legó. ${ }^{1}$

Una de las más importantes diferencias con respecto a nuestro presente, se nota en que, en la Grecia arcaica, la mayoría de los hombres, entrenados desde temprana edad para defender sus territorios o invadir otros, tenían un destino bastante incierto: la muerte era, en esa etapa, familiar, no solo para los guerreros que continuamente la desafiaban, sino también para los habitantes civiles de las comarcas derrotadas: mujeres, niños y niñas, ancianos y ancianas, que corrían el mismo peligro de morir, o la alternativa -a juicio de los vencedores- de la esclavitud.

Fuera del peligro de la guerra, la vida estaba mucho más amenazada que hoy por las enfermedades y las epidemias, de las cuales la medicina actual nos preserva. Muchos niños morían en edad temprana. Entre las mujeres, muchos alumbramientos tenían un fin trágico para ella o para ambos. De manera que la muerte, como decíamos, era algo familiar y esta familiaridad tenía sus consecuencias tanto en la vida privada de las personas como en la vida de la comunidad: el saldo de jóvenes viudos a consecuencia de partos complicados, aunado al de nume- 
rosas viudas (de guerra) jóvenes, presentaba problemas dentro de la organización del "oikós" respectivo y a los individuos involucrados. Una de las consecuencias, entre otras, fue la de casarse varias veces durante su vida.

Así, en Grecia, por varias razones, el matrimonio era un asunto, no de "amor" previo, como suele darse en nuestros días- sino, más bien, de una especie de contrato que, de alguna manera, favorecía a ambas familias. Existía ,por ejemplo, la necesidad de la perpetuación, con hijos e hijas que heredaran -aunque de manera distinta- el patrimonio y preservaran las tradiciones religiosas de la familia, acciones que, a su vez, aseguraban el bienestar del estado en general.

Estos pocos factores, como se ve, influyen en la vida cotidiana de los griegos en general, y van conformando su forma de ser y su idiosincracia. La información sobre las mujeres griegas de la antigüedad, como la de las mujeres de la mayoría de las culturas antiguas o actuales, no es de fácil acceso: esa escurridiza información está inmersa en fuentes producidas en sociedades dominadas por el pensamiento masculino. Las historias del mundo antiguo, como apunta la investigadora Mary Lefkovitz, "tradicionalmente han sido escritas sin mucha referencia a las mujeres. Los mismos antiguos marcaron el patrón de esas historias: son las guerras y la política -no los asuntos sociales o domésticos- las que reclaman la mayor atención de los hombres educados." (Lefkowitz 1987: IX). La otra mitad de la humanidad, la femenina, evidentemente tuvo su influencia en la historia (¿o se debería decir en los hombres que la produjeron?), pero no le fue reconocido su aporte. Su aparición en ella apenas si se da en grado mucho menor, y no siempre es presentada en su valor real.

Así, la historia de las mujeres -o lo poco que de ella existe- hay que leerla entre líneas y extraerla a poquitos, de los muchos y variados documentos que existen: legales, literarios, históricos, científicos, arqueológicos, artísticos...

En la actualidad, existen investigadoras y eruditas de gran calibre -sin olvidar el aporte de numerosos investigadores- que se están entregando a la tarea de dilucidar en lo posible esta historia invisible. Sarah Pomeroy, por ejemplo, se cuestiona, a propósito de la Atenas clásica: "Indudablemente, la producción intelectual y artística de Atenas es deslumbrante. Pero raras veces ha habido mayor discrepancia entre las ventajas culturales que una sociedad presenta y la participación de la mujer en esa cultura. Se podría preguntar ¿Qué hacían las mujeres mientras sus padres, hijos, hermanos, esposos participaban activamente en la política y en lo intelectual? La respuesta no es simple; la evidencia, escasa. Y cada fuente presenta sus propios problemas." (Pomeroy 1976: ix).

En efecto, cada generación de investigadores ha aventurado su propia explicación sobre la vida de las mujeres, algunos con benevolencia, otros juzgándola duramente. Hay estudios de principio de siglo, como el de J. Donaldson, donde ya se admiraba ante la ausencia de mujeres célebres entre las atenienses: "In fact, it is scarcely possible to conceive that such a marvelous crop of remarcable men, renowned in literature and art, could have arisen if all the Athenian mothers were ordinary housewives. But circumstances certainly were exceedingly unfavorable to them; and though there never was in the history of the world such a numerous race of great thinkers, poets, sculptors, painters and architects, in one city at one time as in Athens, not one Athenian woman ever attained to the slightest distinction in any one department od literature, art or science." (Donaldson 1908: 55). 
Hay una "gloria", dice Donaldson, que ellas obtuvieron a la perfección: y la contenida en la Oración Fúnebre de Pericles, que en lo referente dice: "Grande es la gloria de aquella mujer de quien se habla menos entre los hombres, sea para bien, sea para mal."2 (Tucídides).

F.A.Wright va más allá y se pregunta cómo fue que la civilización Griega cayó. No fue, piensa él, por fallas en recursos militares o destreza administrativa, pues la fuerza moral es lo único que cuenta en la historia: "The fact is that the Greek world perished from one main cause a low ideal of womanhood and a degradation of women which found expression both in literature and in social life." (Wrigth 1923:1).

Uno de los estudios más recientes y comprensivos sobre el tema del matrimonio que tocamos arriba, es el de Claudine Leduc (Leduc 1991: 262), desde una perspectiva antropológica, en la cual, tomando en consideración que la joven novia en Grecia siempre era "dada" con una dote, se pregunta "¿Por qué, desde la época homérica, las operaciones matrimoniales en Grecia se inscribían en el campo lexical de dídomi, verbo que, según E. Benveniste, expresa el "don gracioso", antes que en los onéomai/príamai, verbos que significan la compra y el regateo?" En su minuciosa indagación, desde Penélope y Pandora hasta la mujer ateniense, se va descifrando el sistema griego de la reproducción legítima, siempre ligada a la esposa y a los bienes muebles e imnmuebles.

L. Goodwater, refiriéndose a la posición de las mujeres homéricas, generaliza un poco: "Las mujeres griegas emergen de la oscuridad de la prehistoria en la poesía épica de Homero, donde a menudo ellas juegan un rol importante. La Odisea especialmente es notable por sus extraordinarias mujeres: la joven Nausica con su tacto y vivacidad, Calipso y Circe con sus poderes sobrenaturales, las reinas Areté y Helena, que dirigen sus hogares con escasa interferencia masculina, y para culminar, la hábil, inteligente y paciente Penélope, paradigma de la fidelidad conyugal. La evidencia aquí encontrada parece indicar que en el período homérico las mujeres gozaron de una posición social más alta que en cualquier otra época de la historia antigua de Grecia" (Goodwater 1975:1). Esta opinión es muy congruente con un análisis de los personajes principales de las obras, sobre todo si nos atenemos a las mujeres mencionadas, todas de la alta realeza o diosas: no parecen haber estado confinadas al hogar sino que se movían libremente en la sociedad y compartían, en ocasiones, las conversaciones serias de los hombres. También se percibe una actitud delicada hacia las mujeres: aún los pretendientes, que "devoran los bienes del palacio de Odiseo", son respetuosos y corteses con Penélope. Helena le da la bienvenida a Telémaco en su palacio y literalmente guía el curso de la conversación con los tres hombres. Areté goza del respeto, amor y aprecio no sólo de su familia sino del pueblo entero que la honra. Y no olvidemos el gesto del antiguo rey de Itaca, Laertes, quien se abstuvo de unirse con la esclava Euriclea -la cual había comprado "por el precio de veinte bueyes"3 para no despertar los celos de su esposa Anticlea, madre de Odiseo.

Sin embargo, en la llíada encontramos numerosos ejemplos de mujeres que son tomadas prisioneras, y como tales, no importa cuál fuera su rango anterior (noble, libre), eran convertidas en esclavas y quedaban al servicio de su amo. Briseida y Criseida son los ejemplos más notorios. Las mujeres entonces se cuentan entre el botín de guerra. Existen numerosas instancias en que esto sucede: cuando Aquiles celebra los juegos fúnebres en honor a Patroclo, ofrece como premio a los vencedores "trípodes, caballos, bueyes de robusta cabeza, mujeres de hermosa cintura, y luciente hierro". ${ }^{4}$ La "gentileza" de este período, entonces, no era para todas, sino para mujeres de determinadas clases, en determinadas circunstancias. 
Este tipo de apreciación de ejemplos particulares, suministra una idea de la magnitud del aporte que la literatura puede ofrecer a la historia que estamos tratando de rescatar -en lo referente a costumbres y usos con respecto a las mujeres de carne y hueso, en circunstancias no precisamente literarias.

Y ya que hablamos de documentos literarios, se puede pensar, con un buen grado de certeza, que los dramaturgos también, en la delineación de sus personajes femeninos o masculinos, son inevitablemente influenciados por los usos y costumbres de su tiempo -aún cuando tratan de ser fieles a la tradición literaria que permea sus obras. Es evidente que sería peligroso basarse en las heroínas de la tragedia para sacar conclusiones sobre la mujer común y corriente; sin embargo, no cabe duda de que algunos rasgos y actitudes son comunes en ambas; el reto está en analizar cuidadosamente esos rasgos y actitudes y compararlos con evidencia de otros campos, para poder resolver, en parte, el acertijo.

Eurípides, por ejemplo, a quien se ha acusado de misógino, idea personajes femeninos que actúan y reaccionan en forma tan "humana" que podría en realidad considerarse, más bien, su mejor amigo. Ciertamente, sus heroínas son caracteres dramáticos muy claros, y sin embargo, solamente hay que leer un soliloquio de Medea o de Deyanira para darse cuenta de lo íntimamente que Eurípides conocía - o intuía- las angustias y frustraciones de las mujeres de carne y hueso de su época. ¿Y por qué creemos saber esto con certeza? Talvez porque esas mismas angustias y frustraciones, que oímos en boca de las heroínas de Eurípides, son similares a las que hoy, veinticinco siglos después, aquejan a las mujeres de nuestras ciudades y nuestros pueblos.

Una de las fuentes más ricas de que se dispone en la actualidad -aparte de la historia y la literatura- es la evidencia de las bellas artes o documentos de representaciones. Aquí se incluyen desde esculturas y relieves, monedas o pinturas, hasta cerámica, orfebrería y otros.

Los temas favoritos que los pintores áticos plasmaron en sus obras son, por ejemplo, ceremonias de matrimonio, ritos funerarios, escenas de despedida del guerrero por su esposa, mujeres trabajando en diversas ocupaciones características de su género como lecciones de danza, música, y el cuidado de los infantes. Tanto estas figuras, como la forma del envase y su uso, han sido de gran importancia en la recreación de la vida de las comunidades griegas en general y de las mujeres en particular, en el transcurso de las diferentes épocas.

Sin pretender ser exhaustivos, pues quedan muchas fuentes sin siquiera mencionar, examinaremos otras dos de capital importancia: las legislaciones y algunas prácticas religiosas, que contribuyen con información preciosa a nuestra búsqueda de la mujer griega "real".

Los códigos legales espartanos por ejemplo, muy anteriores a los códigos atenienses, dan evidencia, de primer orden, sobre la vida de hombres y mujeres. El gran legislador de Esparta, Licurgo, cuya biografía ha sido transmitida por Plutarco, explica como, para la mujer espartana, la función más importante era la de traer hijos al mundo. Acorde con esto, la ley de Licurgo $^{5}$ sobre funerales honraba a los mayores contribuyentes a la causa espartana, prohibiendo la inscripción del nombre de la persona fallecida sobre la tumba, excepto cuando: a. un hombre había muerto en la guerra o b. una mujer había muerto al dar a luz. En Esparta, evidentemente, prevaleció el interés de la comunidad sobre el del ciudadano. ${ }^{6}$

Otra instancia, de gran interés para el estudio de la mujer griega, se presenta en la antiquísima isla de Creta, en la ciudad de Gortyn, donde se descubrieron partes de un código de leyes del siglo VII a.C. Este código contiene numerosas referencias a la vida en común entre 
hombres y mujeres, algunas con rasgos notablemente liberales hacia éstas. En esta ciudad se dio, como en Esparta, una separación entre los sexos y una relativa libertad de las mujeres. Las mujeres libres, por ejemplo, tenían el derecho de poseer propiedades, controlarlas y aún heredarlas, aunque la herencia del hijo era normalmente mayor que la de la hija. Existía el divorcio, y cuando se producía, ella no solamente se llevaba su propiedad, sino también la mitad del producto del hogar, reconociéndose, en esta forma, el trabajo hecho por la esposa en el oikós; si además, el esposo era el culpable del divorcio, le tocaba pagar una pequeña multa.

En Atenas, de acuerdo con la costumbre y las leyes, se esperaba de una mujer casada que viviera en su casa y no diera problemas: debía mantener la casa en orden, ser custodia de todas las posesiones y valores del hogar, gobernar el numeroso contingente de esclavos, dirigir a las esclavas en sus diversas tareas domésticas, además de hilar y tejer. Tanto Aristóteles ${ }^{7}$ como por otro lado Jenofonte, Aristófanes y algunos oradores ofrecen información detallada sobre estos asuntos.

La religión, tanto la estatal como la privada, siempre tuvo gran importancia en la vida de los griegos. Había rituales y ceremonias para propiciar a los dioses en casi todas las actividades de la polis, así como en las del hogar. Todas, por supuesto, desempeñadas por oficiantes masculinos. Entre los atenienses, sin embargo, las doncellas, esposas del mañana y madres de los futuros ciudadanos, también eran integradas a la ciudad y sus actividades por medio de cierto número de ritos. Estos rituales de las jóvenes constituían un conjunto coherente de prácticas que diferían en naturaleza tanto como en fecha, de acuerdo con las transiciones en el crecimiento de la niña desde la infancia hasta la llegada a la pubertad, momento en que generalmente se casaban. Los rituales en cuestión estaban fuertemente vinculados con la educación y entrenamiento de la futura esposa, madre de la progenie legal.

No solamente en Atenas sino en todas las regiones y en todas las épocas de la historia de Grecia, sobresale siempre la formación práctica que todas las niñas griegas recibían en su hogar, para hacer de ellas excelentes administradoras del patrimonio familiar, amas de casa, y sobre todo, madres de una progenie "legal", progenie que ellas educaban dentro de la "tradición”, con todo lo que esto significa. Sin embargo, se desconoce, por escasez de información, hasta qué punto las jóvenes muchachas de otras partes de Grecia en algún momento tuvieron la posibilidad de recibir una educación más formal, como sí sucedió en la isla de Lesbos. Se sabe con certeza, gracias a la poeta Safo, que allí se habría favorecido por lo menos en parte, la creación poética femenina. ${ }^{8}$ Pero, aunque Safo no es la única, pues existe evidencia de otras poetas en diferentes regiones del mundo griego, esta evidencia es tan esporádica y a veces tan fragmentaria, que hace difícil conocer a fondo esta porción de la historia de la mujer griega.

Es imperativo, finalmente, al hacer recuento de algunas de las fuentes sobre la mujer griega antigua, destacar la importancia del aporte -aunque escaso y fragmentario- de estas poetas que hablan sobre su mundo, sus inquietudes, sus seres queridos. Es indudable que ellas ofrecen una concepción diferente de la vida en el mundo griego antiguo, complementando y enriqueciendo así el punto de vista tradicional.

\section{Notas}

1. En estudios generales sobre diferentes épocas de la cultura griega, existe algún capítulo más o menos sumario sobre la mujer en esa época, como por ejemplo: E. Mireaux, La vida cotidiana en tiempos de Ho- 
mero; R. Flaceliere, La vida cotidiana en Grecia en el siglo de Pericles; H.D.F. Kitto, Los Griegos; M.I. Finley, El mundo de Odiseo, y otros, que ofrecen las posiciones más dispares sobre el tema.

2. Tucídides, Las guerras del Peloponeso, ii,45.

3. Homero, Odisea, I.430.1. Ver igualmente Finley, Op.Cit., 79.

4. Homero, Ilíada, XXIII.259-61.

5. Plutarco, Vidas Paralelas: Licurgo, 27.

6. El poeta elegíaco Tirteo corrobora este énfasis de lo comunitario sobre lo individual en las sociedades espartanas.

7. Aristóteles, La constitución de Atenas, donde hace mención, entre otras, a las leyes del legislador ateniense Solón.

8. Ver nuestro artículo "Temas de las poetas líricas Griegas". En: Memoria del V Congreso de Filología.

\section{Bibliografía}

Donaldson, J. 1908. Woman: her position and influence in ancient Greece and Rome, and among the early Christians. Nueva York: The Gordon Press

Goodwater, L. 1975. Women in Antiquity: An annotated bibliography. Metuchen: The Scarecrow Press Inc.

Homero. Odisea.

Homero. Ilíada.

Leduc, C. 1991. “Comment la donner en mariage?'. Histoire des Femmes, Vol I, L'Antiquité.

Lefkowitz. 1987. Heroines and Histerics. London: St. Martiu's Press. T II

Plutarco. Vidas Paralelas: Licurgo.

Pomeroy, S. 1976. Goddesses, whores, wives and slaves. Nueva York: Shocken Books.

Tucídides. Las guerras del Peloponeso.

Wright, F.A. 1923. Feminism in Greek Literature from Homer to Aristotle. Metuchen: The scarecrow Press Inc. 